NBER WORKING PAPER SERIES

\title{
DIGITAL RIGHTS MANAGEMENT AND THE PRICING OF DIGITAL PRODUCTS
}

\author{
Yooki Park \\ Suzanne Scotchmer \\ Working Paper 11532 \\ http://www.nber.org/papers/w11532
}

\author{
NATIONAL BUREAU OF ECONOMIC RESEARCH \\ 1050 Massachusetts Avenue \\ Cambridge, MA 02138 \\ July 2005
}

We thank seminar and conference participants at U.C. Berkeley, Hitotsubashi University, GRIP, IDEI (Touluose), the NET Institute, University of Washington, U.S.C., CORE, ECARES, WEIS2005, Joan Feigenbaum, Filomena Garcia, Kazuharu Kiyono, Scott Shenker, and especially Emmanuel Farhi, who corrected an error and made many other useful comments. Financial support from the NET Institute (http://www.NETinst.org) is gratefully acknowledged. The views expressed herein are those of the author(s) and do not necessarily reflect the views of the National Bureau of Economic Research.

(C2005 by Yooki Park and Suzanne Scotchmer. All rights reserved. Short sections of text, not to exceed two paragraphs, may be quoted without explicit permission provided that full credit, including $\odot$ notice, is given to the source. 
Digital Rights Management and the Pricing of Digital Products

Yooki Park and Suzanne Scotchmer

NBER Working Paper No. 11532

July 2005

JEL No. L13, L14, L15, K21, O33

\title{
$\underline{\text { ABSTRACT }}$
}

As it becomes cheaper to copy and share digital content, vendors are turning to technical protections such as encryption. We argue that if protection is nevertheless imperfect, this transition will generally lower the prices of content relative to perfect legal enforcement. However, the effect on prices depends on whether the content providers use independent protection standards or a shared one, and if shared, on the governance of the system. Even if a shared system permits content providers to set their prices independently, the equilibrium prices will depend on how the vendors share the costs. We show that demand-based cost sharing generally leads to higher prices than revenue-based cost sharing. Users, vendors and the antitrust authorities will typically have different views on what capabilities the DRM system should have. We argue that, when a DRM system is implemented as an industry standard, there is a potential for "collusion through technology."

\author{
Yooki Park \\ 2204 Glen Avenue \\ Berkeley, CA 94709 \\ yooki@berkeley.edu \\ Suzanne Scotchmer \\ Department of Economics and GSPP \\ 2607 Hearst Avenue \\ University of California \\ Berkeley, CA 94720-7320 \\ and NBER \\ scotch@berkeley.edu
}




\section{Introduction}

As copying of digital content has become easier, content vendors have started to use technical protections rather than relying on legal protections. Technical protections, such as encryption and copy controls, are often lumped together under the name "digital rights management (DRM)." The purpose of this paper is to understand how the transition from legal to technical protections affects the pricing of digital content when the DRM system is implemented by the content vendors themselves rather than by third-party providers.

Competition requires that the vendors set their prices independently. The technical capabilities built into a shared DRM system can either facilitate or obstruct independent pricing of content. However, the outcome in the market will also depend on the vendors' incentive to price competitively, which is affected by how the vendors share the costs of the system. We show that, even with independent price-setting, competition may be compromised by cost sharing.

Technical protections have been evolving since the 1980s. Some have been industry-wide efforts, for example the legally mandated Serial Copy Management System for digital audio tape that was authorized by Congress. This system caused the quality of copies to degrade, so that, as with analog audio tapes, it was hard to make faithful copies of copies. The solution was inelegant at best, but in any case became obsolete due to the proliferation of other digital mediums. Other measures were introduced by vendors themselves, such as the one-installation features imposed by some distributors of computer software. One-installation features were rapidly circumvented.

As content distribution has moved to the Internet, watermark and encryption technologies have developed. A watermark, by analogy with a watermark on paper stationery, is a piece of software code embedded in a program. If illicit copies of the software circulate, the watermark can identify the original buyer or licensee of the copy that is circulating. This may or may not be useful, depending on whether the original buyer or licensee can be held liable. Encryption systems attempt to make digital content uninterpretable or inaccessible without use of a code key. The code key 
generally authorizes playing the content on a specific piece of hardware. For example, the movie industry has developed digital versatile disks (DVDs), which are protected by a technology called the Content Scrambling System (CSS). CSS authorizes access by matching a code embedded in disks to a code embedded in DVD players. Among other purposes, this system ensures that movies released for viewing in one region of the world cannot be viewed in another.

The DVD technology is just one example of a system shared by multiple vendors. Shared DRM systems raise a host of issues regarding ownership, licensing, and price control over players as well as content. For DVDs, both the hardware and software are proprietary, and jointly licensed. On the hardware side, Toshiba administers the licenses, charging per-unit license fees on the sale of DVD media, players, and decoders. The collected fees are then distributed to the patent holders (Hitachi, Matsushita Electric, Time Warner, Toshiba, and Victor) proportionally to each member's holdings in the patent portfolio. On the software side, the Motion Pictures Expert Group (MPEG), which includes manufacturers of players, content companies, and others, use similar terms to license the digital video and audio algorithms (called "codecs") used on DVDs and digital television. Finally, the DVD Copy Control Association (DVD-CCA), controlled primarily by the content industry, licenses the technical protection measure known as the Content Scramble System (CSS). These license fees are linked to players rather than to usage of digital content.

The license on DVD hardware is for a "pool" of patents. Patent pooling for standardization is generally thought to be pro-competitive, barring practices that are anticompetitive or not necessary for the dissemination of intellectual property (Shapiro 2001). The Department of Justice Antitrust Division issued favorable review letters on both the DVD and the MPEG licensing agreements. Notably, however, the review of these agreements focused almost entirely on the competitive effects in player markets. As the licensing fees were only at the encoding/decoding level in the physical media, the effect on the content market was assumed to be minimal, and only briefly considered. Similarly, in VirginMega v. Apple, the French antitrust authorities considered (and dismissed) an antitrust claim to force licensing of FairPlay, the DRM 
system used for Apple's iTunes Music Store. Again, the arguments were focused on the market for players (iPods), rather than the market for music.

In this paper we are concerned with the market for content, rather than with the market for players. From an economic perspective, disentangling the relationship between the the content market and the player market is not trivial, since the demand for players is derived from the demand for content. And from a technical perspective, standardization of technical protections does not necessarily require standardization of players, or vice versa. A given DRM system can be implemented on different players, and a given player can be compatible with different DRM systems.

The main harm that might arise from cartelization of the player market is that it could divert profit from creators, and thus erode the incentive to create. Since the ultimate source of value in the player markets is content, there is a natural antidote to cartelization in the device market: content vendors can implement and maintain their own protection system(s), and players can be made compatible with each vendor's system. However, that solution might introduce new possibilities for competitive harm. The purpose of this paper is to explore the effect on content prices when digital rights management is under the control of the content providers.

Key to our analysis is that the strength of protection is endogenous, and has an effect on prices. We also recognize that vendors must choose whether to implement independent systems or share a common one. An advantage of sharing is that it reduces setup costs. A disadvantage is that the shared system is a more attractive hacking opportunity - a single hack gives access to more content. The shared system must therefore provide a higher level of protection.

In sections 2 and 3 , we show that a threat of circumvention reduces prices relative to perfect legal enforcement. This is because the optimal way to deter circumvention is a combination of lower prices (giving up revenue) and protection (paying costs). However, despite the lower prices, we show that vendors as well as users may prefer technical protection. Even if per-period profit is smaller with technical protections, there is no necessary end to protection by technical means. In section 2 we discuss a single vendor, and in section 3 , we introduce competition between two 
vendors, and show that a threat of circumvention reduces prices whether the vendors compete on prices or collude. We also show that the vendors' incentives to share a system are not perfectly aligned with efficiency. For example, because of price effects, vendors may share a system when it would be less costly to use independent systems. Section 4 illustrates these results in an extended example.

Even though collusion through a shared system may improve the welfare of users relative to perfect legal enforcement, the antitrust authorities may want to set rules about the technology. For example, they may insist on mechanisms that preserve independent pricing. In sections 5 and 6 , we ask to what extent independent pricing is possible with a shared system. We show that, even if the DRM system permits the vendors to set their prices independently, the rules for sharing the costs of the system may have a collusive effect. We show that demand-based cost sharing is more collusive than either revenue-based cost sharing or fixed cost shares.

The ideas in this paper are related to an older literature of the 1980's about the feared harms of photocopying. These include, for example, Novos and Waldman (1984), and Besen and Kirby (1989). These papers were focused mainly on the cost and quality of copies, and how the market for copies affects the price of originals and consumer welfare more generally. In contrast, we assume that digital copies are faithful to the original, and that the cost of copying is endogenous to the level of protection, which we take as an optimizing choice of vendors. More recently, authors have focused on government interventions as a solution to digital copying. For example, Chen and Png (2003) characterize optimal fines for copying, in conjunction with subsidies and taxes, which collectively can mitigate the harms of digital copying.

We follow Conner and Rumelt (1991) in our premise that the threat of copying will cause vendors to lower their prices. (See Sundararajan (2004) for empirical evidence for the existence of DRM price effects.) We follow Belleflamme (2003) in noticing that a shared DRM system affects pricing behavior through the threat of hacking. In Belleflamme's paper, demands would be independent if the vendors had perfect legal enforcement, but demands become interdependent if hacking is a threat. We depart from these papers in assuming that the level of protection (cost of hack- 
ing) is an endogenous choice, and in the welfare questions we address. It may be easier to deter hacking by using independent DRM systems than by using a shared DRM system. We therefore investigate the choice between independent and shared protections, and how it compares to what is optimal. We also investigate the effect on prices of how the shared system is governed, in particular, comparing demand-based cost sharing with revenue-based cost sharing.

\section{The Price-Reducing Effect of Technical Protections}

Probably the most severe criticism of intellectual property as an incentive mechanism is that, in allowing content creators to raise prices to the monopoly level, it creates deadweight loss by excluding users. Will technical protections exacerbate this problem or serve as an antidote? One reason the answer is not obvious is that the strength of protection is an optimizing choice. Even if it is possible to exclude all unauthorized users, the vendor will not typically find it profitable to do so. It may be cheaper to price so that circumvention is deterred rather than to bear the high costs of imple-

menting a hack proof protection system. The incentive to avoid circumvention and to avoid the high cost of protection will have a moderating influence on price.

The assumption here, following Conner and Rumelt (1991), is that a user will buy a legitimate copy instead of circumventing the protection system whenever the price of the legitimate copy is lower than the cost of circumvention. The vendor's optimizing strategy takes account of this. We also assume that, although individual circumventors can circumvent without detection, they cannot make the content freely available on the Internet, or sell a circumvention tool. Those activities would be easily detectable and would put the circumventor in jeopardy under the Digital Millennium Copyright Act.

We show that technical protection will generally result in a lower market price than the monopoly price that would be charged with perfect legal enforcement. In the Appendix, we show that dispersion in the costs of circumvention may exert yet another downward influence on price.

To be more concrete, index agents by $\theta \in[0,1]$, uniformly distributed, and 
suppose that the willingness to pay of agent $\theta$ is $\theta$. For each price $p$, the number of potential users with $\theta \geq p$ is $1-p$. At price $p$, the consumers' surplus of buyers is

$$
s(p)=\int_{p}^{1}(\theta-p) d \theta=\frac{1}{2}(1-p)^{2}
$$

We assume that the marginal cost of copying is zero. Thus, if copying can be controlled, the monopoly price will be $p^{*}=\frac{1}{2}$, which maximizes per-period profit,

$$
\pi(p)=p(1-p)
$$

However, if the copies cannot be controlled, the demand curve for legitimate copies falls to zero. Technical protection measures can mitigate this problem.

Index the strength of protection by $e \in \mathbf{R}_{+}$, and interpret $e$ as the cost of circumvention. Formalizing the intuition that the cost of protection increases superlinearly in the cost of circumvention, denote the cost of implementing protection level $e$ by $K(e)>0$, where $K$ and $K^{\prime}$ are increasing. We shall first suppose that the cost of circumvention is the same for all users, namely, e. After the right holder has chosen the strength of protection, $e$, he must set a price. If $e>p^{*}$, then the optimal price is $p^{*}$. It is therefore wasteful to implement a protection $e>p^{*}$, since the proprietor does not need such strong protection in order to charge the monopoly price. If $e<p^{*}$, the optimal price is $p=e$, the cost of circumvention. At that price, no users will circumvent the technical protection measure in equilibrium.

Thus, for any $e \leq p^{*}$, the firm's profit as a function of $e$ is $\pi(e)-K(e)$, where both $\pi$ and $K$ are increasing, and $\pi$ flattens out for $e>p^{*}$. The profit-maximizing level of protection, say $\hat{e}$, maximizes the difference between profit and cost, and must be lower than $p^{*}$. Thus,

Remark 1. If each user's cost of circumvention is $e$ when the protection level is $e$, the profit-maximizing level of protection $\hat{e}$ satisfies $\hat{e}<p^{*}$, where $p^{*}$ is the profitmaximizing price with perfect legal enforcement. The profit-maximizing price satisfies $\hat{p}=\hat{e}<p^{*}$. There is no circumvention in equilibrium.

Thus the threat of circumvention lowers the price of content. We show in the appendix that dispersion in circumvention costs may lower it even more. 
While the price and profit are lower in each period, the technical protection can continue forever, and may thus be more profitable than perfect legal enforcement, which eventually expires. This may even be true if the costs $K$ are taken into account. Moreover, it is not obvious that the threat of circumvention increases consumer welfare, even though it reduces the per-period price. This is again because the technical protection can continue indefinitely. In fact, a technical protection system can increase both consumer welfare and the proprietor's profit, as compared with perfect legal enforcement for a limited duration. We will show this in an example, but first we make a preliminary comment on the optimal structure of rewards to creation.

For each $p$, let $D W L(p)$ be the lost consumers' surplus at the price $p$ (deadweight loss). Remark 2 says that if a lower price is coupled with longer protection to just the extent that total profit is preserved, and if this has the effect of reducing the deadweight-loss-to-profit ratio, consumers are better off. This ratio test is satisfied for linear demand curves, as assumed here.

By assuming that revenue is held fixed, Remark 2 focuses on the optimal structure of rewards ex post. It allows us to consider ex post efficiency without considering the ex ante incentive to create. In the remainder of this paper, where we consider governance structures for sharing technical protections, the ex ante and ex post efficiency issues are not so easy to disentangle.

Remark 2. Suppose a legal regime lasts $T^{*}$ discounted years ${ }^{1}$ with monopoly price $p^{*}$, and suppose a technical protection regime lasts $T(e)$ discounted years, $T(e)>T^{*}$ with price $p(e)$ that satisfies $p(e)<p^{*}$. Suppose that the revenue earned in both regimes is the same, $\pi(p(e)) T(e)=\pi\left(p^{*}\right) T^{*}$. Then consumers are better off if and

\footnotetext{
${ }^{1}$ The length of protection $T$ is taken to be already discounted. If the statutory length of protection is $\tau$, and the discount rate is $r$, then $T=\int_{0}^{\tau} e^{-r t} d t$. The discounted length of protection, $T$, cannot be larger than $\frac{1}{r}$, which corresponds to $\tau=\infty$.
} 
only if ${ }^{2}$

$$
\frac{D W L\left(p^{*}\right)}{\pi\left(p^{*}\right)}>\frac{D W L(p(e))}{\pi(p(e))}
$$

Proof. Since $p(e)<p^{*}$, the per-period consumers' surplus is higher, $s(p(e))>s\left(p^{*}\right)$. With perfectly enforceable copyrights, total consumers surplus is

$$
s\left(p^{*}\right) T^{*}+\left(\frac{1}{r}-T^{*}\right) s(0),
$$

where $s(0)=\frac{1}{2}$ is the per-period consumers' surplus after the protection ends, when the product will be "sold" at the competitive price, zero. Analogously, we shall write

$$
s(p(e)) T(e)+\left(\frac{1}{r}-T(e)\right) s(0)
$$

for consumers' surplus with the technical protection in place. Consumers are better off with technical protection of length $T(e)$ if and only if:

$$
\left[s(0)-s\left(p^{*}\right)\right] T^{*}-[s(0)-s(p(e))] T(e)>0
$$

Remark 2 follows from the observation that the consumers' surplus that is lost due to higher than competitive prices is equal to profit plus deadweight loss. Therefore,

$$
\begin{aligned}
& s(0)-s\left(p^{*}\right)=\pi\left(p^{*}\right)+D W L\left(p^{*}\right) \\
& s(0)-s(p(e))=\pi(p(e))+D W L(p(e))
\end{aligned}
$$

Then, using $T^{*} \pi\left(p^{*}\right)=T(e) \pi(p(e))$, the inequality (2.3) holds if and only if $(2.2)$ holds.

However, this conceptual experiment is not quite the right one for comparing costless enforcement of copyrights with technical protections. Technical protections can continue forever - protection will not end at the duration $T(e)$ required for the

\footnotetext{
${ }^{2}$ The ratio test for whether a simultaneous price reduction and lengthening of protection helps consumers was introduced in the antitrust context by Kaplow 1984 to evaluate the desirability of licensing practices, and in the patent design context by Tandon (1982) and many subsequent authors (see Scotchmer (2005), chapter 4) to evaluate the desirability of making patents broad or narrow. The notable feature of the ratio test is that the comparison is reduced to a static one. Even though deadweight loss lasts longer in the technical protection regime, we only have to observe that the ratio of deadweight loss to profit is reduced in each period in order to know whether in total the technical protection regime is better for consumers.
} 
profit equivalence. Further, technical protections are costly. Nevertheless, this line of reasoning correctly suggests that technical protections can sometimes make both creators and consumers better off. We show this with an example.

Example: As argued above, if there is no dispersion of circumvention costs, the optimal price with a technical protection is $p(e)=e$. Thus, consumers' surplus per period of time with technical protection is $s(p(e))=\frac{1}{2}(1-e)^{2}$.

Social surplus is greater with technical protection than with perfect legal enforcement if

$$
T^{*} s\left(p^{*}\right)+\left(\frac{1}{r}-T^{*}\right) s(0) \leq \frac{1}{r} s(p(e))
$$

Profit is greater with technical protection than with perfect legal enforcement if

$$
T^{*}\left[p^{*}\left(1-p^{*}\right)\right] \leq \frac{1}{r}[e(1-e)-K(e)]
$$

Let the cost function $K$ be given by

$$
K(e)=\left\{\begin{array}{ccc}
\frac{1}{80} & \text { if } \quad e \leq \frac{1}{4} \\
e^{2}-\frac{1}{20} & \text { if } \quad e>\frac{1}{4}
\end{array}\right.
$$

The level of protection that maximizes $e(1-e)-K(e)$ is $e=\frac{1}{4}$. The conditions (2.5) and (2.4) on profit and social surplus are satisfied if the discount rate and length of legal protection satisfy

$$
\frac{7}{12}<r T^{*}<\frac{7}{10}
$$

\section{Independent Protections versus Shared Protections}

We now turn from monopoly to oligopoly, and consider how the pricing of digital content depends on the protection system. Prices will depend on whether the content providers implement independent systems or share a common one. If they share a common one, the market outcome will depend on whether they price independently, and on how they share the costs of the protection system. 
The table below lays out the cases for comparison, partly as a guide to notation. Vendors may implement independent systems to protect their content or a shared one, and they might price independently or collude. When vendors share a protection system, they must somehow cover their shared protection costs. The three notations $\hat{I}, \tilde{I}, \bar{I}$ refer to different ways of sharing cost while pricing independently: fixed shares, or cost shares equal to demand shares or revenue shares, respectively. This section discusses the price outcomes in the regimes where the cost sharing considerations do not arise, including the case of a shared system leading directly to collusive pricing $(J)$. The next section then provides an illustrative example of the results. In section 5 we turn to the impact of cost sharing rules.

\begin{tabular}{|c||c|c|c|}
\hline \multirow{2}{*}{ Pricing: } & \multicolumn{3}{|c|}{ Protections: } \\
\cline { 2 - 4 } & $\begin{array}{c}\text { None } \\
\text { Legal Enforcement }\end{array}$ & $\begin{array}{c}\text { Independent } \\
\text { System }\end{array}$ & Shared System \\
\hline \hline Independent & $\hat{I}$ & $I$ & $\hat{I}, \tilde{I}, \bar{I}$ \\
\hline Joint (collude) & $\hat{C}$ & $C$ & $J$ \\
\hline
\end{tabular}

A conclusion of this section is that a shared system can be socially preferable to independent systems even if the vendors use the shared system to collude. Moreover, the shared system can be superior even in the narrow sense of reducing prices for content, even if sharing does not significantly lower the costs of protection. The lower prices are due to the price-moderating effect of a threat of circumvention, which operates more powerfully if the vendors share a system than if they use independent systems. A shared system is more tempting to hackers, since a single hack gives access to more content. To deter circumvention, the shared protection must be stronger, hence more costly. Instead of bearing the high cost of joint protection, it may be cheaper for the vendors to deter circumvention by lowering prices instead.

Even if sharing does not reduce prices, due to collusion, it may have the social and private benefit of reducing the total cost of protection, since setup costs are only paid once instead of twice. Balanced against the saving in fixed costs is the fact that marginal costs of deploying more protection will be higher in a shared system.

Suppose that the firms face demands $D_{1}\left(p_{1}, p_{2}\right), D_{2}\left(p_{1}, p_{2}\right)$, each decreasing in its own price and increasing (nondecreasing) in the other firm's price. Some people will 
buy both products, but others will buy only one of the products. In order to focus on the pure effects of cost sharing or other arrangements that affect prices, we will assume that the vendors are in symmetric positions, and we focus on symmetric equilibria. Asymmetries between the vendors, such as in the popularity of their content, will have additional effects not considered here.

The cost of protection will again be given by a positive function $K$, which includes fixed costs and increasing marginal costs as the strength of protection increases. We again assume that there is no dispersion in circumvention costs, and that the level of protection, $e$, is calibrated to be the cost of circumvention.

We will find it useful to define revenue functions and profit functions:

$$
\begin{aligned}
& R_{i}\left(p_{1}, p_{2}\right)=p_{i} D_{i}\left(p_{1}, p_{2}\right) \quad \text { for } i=1,2 \\
& \Pi_{i}^{I}\left(p_{1}, p_{2}\right)=R_{i}\left(p_{1}, p_{2}\right)-K\left(p_{i}\right) \quad \text { for } i=1,2
\end{aligned}
$$

We assume throughout that at a sufficiently high price, each firm's demand, hence revenue, becomes zero, regardless of the other firm's price.

In the profit functions $\Pi_{i}^{I}$ (where " $I$ " standards for "independent"), we have entered $p_{i}$ as the argument in $K$, recognizing that the optimal choice of price and protection satisfies $e=p_{i}$ for firm $i$. "Unused" protection, $e>p_{i}$, is wasteful, and less protection, $e<p_{i}$, would lead to zero revenue.

We define the following equilibria:

- The prices $\left(p^{\hat{I}}, p^{\hat{I}}\right)$ are an equilibrium with perfect legal enforcement if $R_{1}\left(p^{\hat{I}}, p^{\hat{I}}\right) \geq$ $R_{1}\left(p, p^{\hat{I}}\right)$ for all $p \geq 0$ and symmetrically for firm 2 .

- The prices $\left(p^{I}, p^{I}\right)$ are an equilibrium with independent technical protections if $\Pi_{1}^{I}\left(p^{I}, p^{I}\right) \geq \Pi_{1}^{I}\left(p, p^{I}\right)$ for all $p \geq 0$, and symmetrically for firm 2 .

We will assume that these symmetric equilibria exist.

As a benchmark, now suppose that the firms collude, even though they implement independent protections. We will assume that the profit-maximizing prices are symmetric. Let $\left(p^{\hat{C}}, p^{\hat{C}}\right)$ be the prices that maximize

$$
\Pi^{\hat{C}}\left(p_{1}, p_{2}\right)=R_{1}\left(p_{1}, p_{2}\right)+R_{2}\left(p_{1}, p_{2}\right)
$$


which is the joint profit with perfect legal enforcement. Let $\left(p^{C}, p^{C}\right)$ be the prices that maximizes joint profit with independent protections, defined as

$$
\Pi^{C}\left(p_{1}, p_{2}\right)=R_{1}\left(p_{1}, p_{2}\right)+R_{2}\left(p_{1}, p_{2}\right)-K\left(p_{1}\right)-K\left(p_{2}\right)
$$

For the case of shared protection, let $\left(p^{J}, p^{J}\right)$ be the collusive prices that maximize joint profit

$$
\Pi^{J}\left(p_{1}, p_{2}\right)=R_{1}\left(p_{1}, p_{2}\right)+R_{2}\left(p_{1}, p_{2}\right)-K\left(p_{1}+p_{2}\right)
$$

Here we assume that the vendors will choose high enough protection so that all hacking is deterred, which requires that $p_{1}+p_{2} \leq e$. We have again substituted $p_{1}+p_{2}$ for $e$ in the cost function. The only plausible alternative would be for the vendors to choose a level of protection that is higher than each individual price but lower than the sum. We assume this is not optimal. With this lower level of protection, some consumers who would otherwise pay for a single product would switch to hacking, and receive both products at the hacking cost $e$. And consumers who would otherwise pay for both products would surely switch to hacking instead of paying. Both changes in behavior are costly to the producers, especially if many consumers would buy both products when $p_{1}+p_{2} \leq e$.

To compare prices, we need some additional assumptions. The price differences are due to the fact that, with protection, price can only be increased by incurring the marginal cost of more protection.

Assumption 1. Given the revenue and profit functions defined above:

(a) The cross-partial derivatives of the revenue and profit functions (3.1) and (3.5) are nonnegative.

(b) Revenue and profit functions (3.1), (3.2), (3.3), (3.4), and (3.5) are quasiconcave on the domains where they are nonnegative. 
(c) The own derivatives of (3.1) and (3.2), (e.g. $\frac{\partial}{\partial p_{1}} \Pi_{1}^{I}\left(p_{1}, p_{2}\right)$,) are decreasing in the symmetric price $p$. That is, for $i=1,2$,

$$
\begin{aligned}
\frac{\partial^{2}}{\partial p_{1}^{2}} \Pi_{i}^{I}\left(p_{1}, p_{2}\right)+\frac{\partial^{2}}{\partial p_{1} \partial p_{2}} \Pi_{i}^{I}\left(p_{1}, p_{2}\right) & <0 \\
\frac{\partial^{2}}{\partial p_{1}^{2}} R_{i}\left(p_{1}, p_{2}\right)+\frac{\partial^{2}}{\partial p_{1} \partial p_{2}} R_{i}\left(p_{1}, p_{2}\right) & <0
\end{aligned}
$$

The cross-partial property in assumption 1(a) also follows for profit functions (3.2), (3.3), and (3.4). Assumption 1(a) asserts that prices are strategic complements. Assumption 1(c) ensures that the symmetric equilibria are unique. ${ }^{3}$

Proposition 1 (A threat of circumvention reduces prices). Suppose that Assumption 1 holds.

(a) The symmetric prices that result from perfect legal enforcement are higher than those that result when vendors use independent DRM systems. That is, $p^{\hat{I}}>p^{I}$.

(b) The symmetric prices that maximize joint profit with perfect legal enforcement are higher than those that maximize joint profit with independent DRM systems, and the latter are higher than the symmetric prices that maximize joint profit with a shared DRM system. That is, $p^{\hat{C}}>p^{C}>p^{J}$.

Proof. (a) We use the Corollary to Theorem 6 of Milgrom and Roberts, 1990 and Theorem 13 of Milgrom and Shannon, 1994. To show $p^{\hat{I}}>p^{I}$, write

$$
R_{1}\left(p_{1}, p_{2}\right)+t K\left(p_{1}\right)
$$

for firm 1's profit function (symmetrically, firm 2's profit function), and let $t \in[-1,0]$ define a class of games. Then $t=-1$ is the profit function (3.2) for the game with separate technical protections, and $t=0$ is the profit function (3.1) for the game with perfect legal enforcement. The class of games defined by $t \in[-1,0]$ are symmetric,

\footnotetext{
${ }^{3}$ Suppose that the game is defined by functions $\Pi_{1}\left(p_{1}, p_{2}\right), \Pi_{2}\left(p_{1}, p_{2}\right)$, which are symmetric, and that assumption 1 holds. Suppose now that there are two equilibria, $(\hat{p}, \hat{p})$ and $(\tilde{p}, \tilde{p})$. Then $\frac{\partial \Pi_{1}}{\partial p_{1}}(\tilde{p}, \tilde{p})=\frac{\partial \Pi_{1}}{\partial p_{1}}(\hat{p}, \hat{p})=0$, so $\frac{\partial \Pi_{1}}{\partial p_{1}}(\tilde{p}, \tilde{p})-\frac{\partial \Pi_{1}}{\partial p_{1}}(\hat{p}, \hat{p})=0=\int_{\hat{p}}^{\tilde{p}}\left[\frac{\partial \Pi_{1}^{2}}{\partial p_{1} \partial p_{1}}(t, t)+\frac{\partial \Pi_{1}^{2}}{\partial p_{1} \partial p_{2}}(t, t)\right] d t$, which is a contradiction.
} 
(smooth) supermodular, and satisfy the single crossing property. Therefore the unique symmetric equilibrium prices of the games defined by $t$ are increasing in $t$, so $p^{\hat{I}} \geq p^{I}$. One can see from the derivatives that the inequality is strict.

(b) For $p^{\hat{C}}>p^{C}$, write the maximand as

$$
R_{1}\left(p_{1}, p_{2}\right)+R_{2}\left(p_{1}, p_{2}\right)+t\left[K\left(p_{1}\right)+K\left(p_{2}\right)\right]
$$

This maximand is supermodular in $\left(p_{1}, p_{2}\right)$ and has increasing differences in $\left(p_{1}, p_{2} ; t\right)$, (Milgrom and Shannon, 1994, Theorem 6), so the maximum is monotonic in $t$ (Milgrom and Shannon, 1994, Theorem 5). The value $t=-1$ represents the optimum of (3.4) and the value $t=0$ represents the optimum of (3.1). Therefore $p^{\hat{C}} \geq p^{C}$, and, again, one can see from the derivative that the inequality is strict.

To show $p^{C}>p^{J}$ write

$$
R_{1}\left(p_{1}, p_{2}\right)+R_{2}\left(p_{1}, p_{2}\right)-\left[K\left(p_{1}+p_{2}\right)+t\left(K\left(p_{1}\right)+K\left(p_{2}\right)-K\left(p_{1}+p_{2}\right)\right)\right]
$$

Again, by hypothesis this maximand has increasing differences in $\left(p_{1}, p_{2} ; t\right)$, so the maximum is monotonic in $t$ (Milgrom and Shannon, 1994, Theorems 5 and 6). The optimum of (3.4) is the maximum where $t=1$, and the optimum of (3.5) is the maximum when $t=0$. The result follows.

A shared system can be socially more efficient than independent systems even if the vendors use the shared system to collude, and even if the collusive prices are higher than with independent systems. This is because the shared system saves costs. However, even if the firms can use a shared system to collude, they will not necessarily make the efficient decision whether to share.

In the following remark, by competition we mean independent pricing with independent protection systems, and by collusion we mean maximization of joint profit, using a shared system. If one is more profitable than the other, then presumably that is the system the vendors would choose, even if it not efficient. Efficiency in this remark means from an ex post point of view, namely, that the deadweight loss plus the cost of the protection system is smaller in the more efficient arrangement. However, reducing profit may reduce the incentives to create content, which also entails a social cost. In this remark, we are not taking that cost into account. 


\section{Remark 3 (Ex post efficiency, and the choice among protection systems).}

(a) If $p^{I}>p^{J}$ and $2 K\left(p^{I}\right)<K\left(2 p^{J}\right)$, competition is more profitable for content providers than collusion, although collusion might be socially more efficient.

(b) If $p^{I}>p^{J}$ and $2 K\left(p^{I}\right)>K\left(2 p^{J}\right)$, competition might be more profitable for the content providers than collusion, although collusion is socially more efficient.

(c) If $p^{I}<p^{J}$ and $2 K\left(p^{I}\right)>K\left(2 p^{J}\right)$, collusion is more profitable for the content providers than competition, although competition might be socially more efficient.

(d) If $p^{I}<p^{J}$ and $2 K\left(p^{I}\right)<K\left(2 p^{J}\right)$, collusion might be more profitable for the content providers than competition, although competition is socially more efficient.

The example in the next section illustrates that the vendors will not always choose the more efficient arrangement as to sharing or using independent DRM systems.

\section{Collusion versus Independent Pricing: An Example}

In the previous section we compared the prices charged by vendors who can perfectly enforce their legal rights and with the prices charged by vendors who use independent protection systems. We also compared collusive prices, assuming, respectively, that the content of vendors is legally enforced, that they use independent protection systems, and that they share a common system. Proposition 1 summarizes these comparisons, but conspicuously omits a comparison of collusive prices with competitive prices, when using DRM. Oddly, the comparison can go either way, as we now show. More precisely, the competitive prices $p^{I}$ (also $p^{\hat{I}}$ ) can be lower or higher than prices with a shared system and collusion, $p^{J}$.

Because the products are substitutes, collusion has a tendency to raise price relative to independent pricing with perfect legal enforcement, $p^{\hat{I}}$, and relative to competition with legal enforcement, $p^{I}$. But because joint protection is more costly 
than independent protection (or no protection), there is an offsetting effect. Perhaps counterintuitively, it may occur that $p^{J}<p^{\hat{I}}, p^{I}$. As a consequence, consumers can benefit from consolidation through a DRM system, even if it leads to collusive pricing.

We now give an example to show what the comparison depends on. Consider two firms 1,2 , each facing a demand for its content that depends negatively on its own price and positively on the competitor's price. Let firm 1's demand be defined as

$$
D_{1}\left(p_{1}, p_{2}\right)=\max \left\{1-p_{1}+c p_{2}, 0\right\}
$$

where $0 \leq p_{1}, p_{2} \leq 1$, and $0 \leq c \leq 1$. The parameter $c$ determines the degree of substitutability between the two products. Firm 2's demand is symmetrically defined.

Let the costs of protection be defined by

$$
K(e)=k+\kappa e^{2}
$$

so that $k$ is a fixed cost and $2 \kappa e$ is the marginal cost of increasing the cost of circumvention.

When the firms compete using independent protection systems, firm 1's best response function is $\frac{1+c p_{2}}{2+2 \kappa}$ (symmetrically for firm 2), and the symmetric Nash equilibrium prices and per-firm profits are given by:

$$
\begin{aligned}
p^{I} & =\frac{1}{2+2 \kappa-c} \\
\pi^{I} & =\frac{1+\kappa}{(2+2 \kappa-c)^{2}}-k
\end{aligned}
$$

As noted previously, technical protection moderates the price of content (with $\kappa>0$ ), compared to perfect legal protection. The equilibrium price with perfect legal enforcement would be $p^{\hat{I}}=\frac{1}{2-c}$, which is higher than $p^{I}$.

Suppose now that firms own a technical protection system as a joint monopolist. The level of protection must satisfy $e \geq p_{1}+p_{2}$, and this inequality will be satisfied as an equality. The firms maximize joint profit (3.5). The symmetric profit-maximizing prices, quantities, and total profits are:

$$
\begin{aligned}
p^{J} & =\frac{1}{2+4 \kappa-2 c} \\
\pi^{J} & =\frac{2(1-c)}{(2+4 \kappa-2 c)^{2}}-k
\end{aligned}
$$


Proposition 2 (Pricing with linear demand, quadratic protection costs). In the context of the above model with linear demand and quadratic protection costs, the profit-maximizing prices with a shared protection system, $\left(p^{J}, p^{J}\right)$, are higher than the competitive prices with separate protection systems, $\left(p^{I}, p^{I}\right)$, if $2 \kappa<c$, and otherwise are lower.

The proof follows directly from comparing the expressions (4.2) and (4.4). The price-moderating effect of the shared protection is increasing in $\kappa$, but the collusive effect of joint pricing is increasing in $c$. The latter effect dominates if $2 \kappa<c$.

Aside from any strategic benefit due to coordinating prices, vendors have an incentive to share a technical protection system in order to save fixed costs. This incentive is offset by the higher marginal costs of protection in a shared system, which will also cause the price to be lower. As noted in remark 4, therefore, depending on the relative magnitudes of these effects, firms may or may not prefer the more socially efficient system. Moreover, a shared protection system may be beneficial to both consumers and vendors.

Suppose, for example, that the demands for the content are independent $(c=0)$ and marginal costs for protection are positive, $(\kappa>0$.) According to Proposition 2, the $p^{I}>p^{J}$, so consumers prefer the shared system, even with collusive pricing. Now consider the firm's profits given by (4.3) and (4.5), noting that each firm gets half the profit. Vendors prefer collusion in a shared system if

$$
\frac{1}{2(1+\kappa)}-\frac{1}{2(1+2 \kappa)^{2}}<k
$$

Therefore, if (4.6) holds, vendors and consumers both prefer shared protection. From an aggregated standpoint, shared protections are better when $2 s\left(p^{J}\right)+\pi^{J}>$ $2 s\left(p^{I}\right)+2 \pi^{I}$, which holds if

$$
\frac{(1+2 \kappa)^{2}}{4(1+\kappa)^{2}}-\frac{(1+4 \kappa)^{2}}{4(1+2 \kappa)^{2}}+\frac{1}{2(1+\kappa)}-\frac{1}{2(1+2 \kappa)^{2}}<k
$$

Because the difference between the first two terms of (4.7) is negative, (4.7) holds if (4.6) holds, but not necessarily vice versa. Thus, for a wide range of parameter values, firms will be too reluctant to share a system, relative to what is efficient. 
Suppose now that $c>0$ and $\kappa=0$. Then $p^{I}>p^{J}$, so consumers are unambiguously worse off with collusion than with competitive pricing and independent protections. Comparing (4.3) and (4.5), for all $k \geq 0, c>0$, we find that $\pi^{I}<\frac{\pi^{J}}{2}$. Since the collusive prices are higher than the competitive prices, and the total costs are smaller, profits are higher with joint protection.

Perhaps the most notable conclusion is that, depending on the relative magnitude of the collusive effects and cost advantages, collusive pricing with a shared protection system may be socially and privately preferable to the competitive outcome with independent protections.

\section{Independent Pricing and Cost Sharing}

We have so far compared competition when vendors use independent systems with collusion when they use a shared system. However, these are not the only options. In those situations where collusive pricing is not socially preferable, it may be possible to have both the cost advantages of a shared system and the competitive benefits of independent pricing. In this section we ask whether, by appropriate choice of the technology, competition can be maintained even though the vendors share a DRM system. One can imagine a shared technology that gives to each vendor the ability to enter its own price, to be administered by the system. With such a technology, pricing is independent. However, the vendors must share the costs of the system, and the cost sharing arrangement may itself lead to collusion.

We center our discussion on three cost sharing schemes:

1. independent pricing with demand-based cost shares (cost shares equal to shares of total downloads) (notation $\tilde{I}$ );

2. independent pricing with revenue-based cost shares (cost shares equal to revenue shares) (notation $\bar{I})$;

3. independent pricing with fixed cost shares (notation $\hat{I}$ ).

We use $p^{J}$ as a collusive benchmark against which to consider pricing under these cost sharing rules. Together with the level of protection, e, each cost sharing 
rule leads to a different profit function, and therefore a different game played by the content providers. Proposition 3 suggests that the three cost sharing schemes are listed above in decreasing order of collusiveness. It is almost obvious that option 3, fixed cost shares, leads to the outcome with perfect legal enforcement, $p^{\hat{I}}$. More interesting are cases 1 and 2 .

To define the games that result from the first and second cost sharing rules, we define cost shares $\tilde{\alpha}$ and $\bar{\alpha}$ as follows for firm 1 (and symmetrically for firm 2 ).

$$
\begin{aligned}
& \tilde{\alpha}_{1}\left(p_{1}, p_{2}\right)=\left\{\begin{array}{ccc}
\frac{D_{1}\left(p_{1}, p_{2}\right)}{D_{1}\left(p_{1}, p_{2}\right)+D_{2}\left(p_{1}, p_{2}\right)} & \text { if } & D_{1}\left(p_{1}, p_{2}\right)+D_{2}\left(p_{1}, p_{2}\right)>0 \\
1 / 2 & \text { if } & D_{1}\left(p_{1}, p_{2}\right)+D_{2}\left(p_{1}, p_{2}\right)=0
\end{array}\right. \\
& \bar{\alpha}_{1}\left(p_{1}, p_{2}\right)=\left\{\begin{array}{cll}
\frac{R_{1}\left(p_{1}, p_{2}\right)}{R_{1}\left(p_{1}, p_{2}\right)+R_{2}\left(p_{1}, p_{2}\right)} & \text { if } & R_{1}\left(p_{1}, p_{2}\right)+R_{2}\left(p_{1}, p_{2}\right)>0 \\
1 / 2 & \text { if } & R_{1}\left(p_{1}, p_{2}\right)+R_{2}\left(p_{1}, p_{2}\right)=0
\end{array}\right.
\end{aligned}
$$

The conclusions below about independent pricing can largely be understood by examining the cost sharing rules. The demand-based cost share $\tilde{\alpha}_{1}$ is increasing with demand $D_{1}$ and decreasing with the other firm's demand, $D_{2}$, hence decreasing with the vendor's own price $p_{1}$. By increasing price, the vendor reduces its cost share, which makes a high price more attractive than it otherwise would be. This suggests that with demand-based cost sharing, prices will be higher than with fixed cost shares.

The revenue-based cost share $\bar{\alpha}_{1}$ can be either increasing or decreasing with $p_{1}$, since $R_{1}$ can be either increasing or decreasing with $p_{1}$. Even if the cost share $\bar{\alpha}_{1}$ decreases with $p_{1}$ like $\tilde{\alpha}_{1}$, it decreases at a smaller rate - revenue decreases less quickly than demand as price rises, because the increase in price offsets the fall in demand. This suggests that there is less incentive to raise price with revenue-based cost sharing than with demand-based cost sharing, and that prices will be lower. These intuitions are correct, but they are incomplete because they do not take account of the strategic interaction between the firms, and they do not use the fact that the firms can constrain their pricing by choice of $e$, the level of protection.

The profit functions for firm 1 (symmetrically for firm 2) in games 1, 2 and 3 are the following, conditional on the cost of protection $K(e)$ : 


$$
\begin{aligned}
& \tilde{\pi}_{1}\left(p_{1}, p_{2} ; e\right)=\left\{\begin{array}{cll}
R_{1}\left(p_{1}, p_{2}\right)-\tilde{\alpha}_{1}\left(p_{1}, p_{2}\right) K(e) & \text { if } & p_{1}+p_{2} \leq e \\
-(1 / 2) K(e) & \text { if } & p_{1}+p_{2}>e
\end{array}\right. \\
& \bar{\pi}_{1}\left(p_{1}, p_{2} ; e\right)=\left\{\begin{array}{cll}
R_{1}\left(p_{1}, p_{2}\right)-\bar{\alpha}_{1}\left(p_{1}, p_{2}\right) K(e) & \text { if } & p_{1}+p_{2} \leq e \\
-(1 / 2) K(e) & \text { if } & p_{1}+p_{2}>e
\end{array}\right. \\
& \hat{\pi}_{1}\left(p_{1}, p_{2} ; e\right)=\left\{\begin{array}{cll}
R_{1}\left(p_{1}, p_{2}\right)-\hat{\alpha}_{1} K(e) & \text { if } & p_{1}+p_{2} \leq e \\
-\hat{\alpha}_{1} K(e) & \text { if } & p_{1}+p_{2}>e
\end{array}\right.
\end{aligned}
$$

where $\left(\hat{\alpha}_{1}, \hat{\alpha}_{2}\right)$ are fixed and sum to 1 .

The sequence of choices in each of the three games is that the vendors first choose $e$, which is then fixed, after which they compete on price. ${ }^{4}$ In the three different games, the vendors maximize the different profit functions defined by (5.3). In each game, the no-hacking constraint implies that the symmetric price is bounded above by $e / 2$. Before coming to that, however, in Proposition 3 we sort out the pure effect of cost sharing on price competition, ignoring the no-hacking constraint $p_{1}+p_{2} \leq e$.

Consider the following profit functions for firm 1 (symmetrically for firm 2), which are the same as (5.3), but without the no-hacking constraint $p_{1}+p_{2} \leq e$.

$$
\begin{aligned}
& \tilde{\pi}_{1}^{K}\left(p_{1}, p_{2}\right)=R_{1}\left(p_{1}, p_{2}\right)-\tilde{\alpha}_{1}\left(p_{1}, p_{2}\right) K \\
& \bar{\pi}_{1}^{K}\left(p_{1}, p_{2}\right)=R_{1}\left(p_{1}, p_{2}\right)-\bar{\alpha}_{1}\left(p_{1}, p_{2}\right) K \\
& \hat{\pi}_{1}^{K}\left(p_{1}, p_{2}\right)=R_{1}\left(p_{1}, p_{2}\right)-\hat{\alpha}_{1} K
\end{aligned}
$$

Let $p^{\tilde{I}}(K), p^{\bar{I}}(K), p^{\hat{I}}(K)$ be, respectively, symmetric equilibrium prices in the games defined by these profit functions. It is clear that for all $K$, the symmetric equilibrium $p^{\hat{I}}(K)$ of the game with profit functions $\hat{\pi}_{1}^{K}, \hat{\pi}_{2}^{K}$ satisfies $p^{\hat{I}}(K)=p^{\hat{I}}$, where $p^{\hat{I}}$ is the symmetric equilibrium price defined above for perfect legal enforcement. To compare prices, we make additional assumptions on the profit functions.

\footnotetext{
${ }^{4}$ One of the difficulties in the asymmetric case is that the vendors may disagree about the level of protection in the first place, which would introduce a bargaining problem. By focusing on the symmetric case, we can separate out our investigation of cost sharing rules, without cluttering the analysis with that bargaining issue.
} 
Assumption 2. For the revenue and profit functions defined in (3.1) and (5.4),

(a) The cross-partial derivatives are non-negative.

(b) The profit functions are quasiconcave in own price on domains where profit is positive. $^{5}$

(c) The own derivatives of the profit functions, such as $\frac{\partial}{\partial p_{1}} \tilde{\pi}_{1}^{K}(p, p)$, are decreasing in the symmetric price $p$. That is,

$$
\frac{\partial^{2}}{\partial p_{1}^{2}} \tilde{\pi}_{1}^{K}(p, p)+\frac{\partial^{2}}{\partial p_{1} \partial p_{2}} \tilde{\pi}_{1}^{K}(p, p)<0
$$

(d) Firm 1's revenue function (similarly, firm 2's revenue function) satisfies

$$
\begin{array}{ll}
\frac{\partial}{\partial p_{1}} R_{1}(p, p)>0 & \text { for } p<p^{\hat{I}} \\
\frac{\partial}{\partial p_{1}} R_{1}(p, p)<0 & \text { for } p>p^{\hat{I}}
\end{array}
$$

These assumptions are non-primitive, but not unreasonable, at least in the domains that affect optimizing choices. As before, assumption 2(c) implies that there is a unique symmetric equilibrium. Note that, as before, we are restricting attention to the case where symmetric equilibria exist, which is, among other things, an assumption on the level of costs. If costs are high enough that the symmetric prices result in negative profits, but that a single firm could make positive profits, there is no symmetric equilibrium, and possibly no equilibrium in pure strategies at all, due to the discontinuity in the profit functions.

Proposition 3 (The pure effect of cost sharing on prices). Suppose that assumption 2 holds. Given $K>0$, let $p^{\hat{I}}, p^{\bar{I}}(K), p^{\tilde{I}}(K)$ be unique symmetric equilibria of the games defined by the profit functions (5.4), and suppose that the vendors earn positive profits in the equilibria. Then $p^{\hat{I}} \leq p^{\bar{I}}(K)<p^{\tilde{I}}(K)$ with strict inequality if the cross partials of revenue functions are positive. Further, $p^{\hat{I}(\cdot)}, p^{\tilde{I}(\cdot)}$ are increasing.

\footnotetext{
${ }^{5}$ But it would not be reasonable to assume that the profit functions are quasiconcave on the whole domain. Consider the profit function $\bar{\pi}_{1}^{K}$. If firm 2 is pricing so that it earns positive revenue, firm 1 can earn zero revenue and zero profits by pricing very low or very high. At intermediate prices that generate revenue, firm 1's profit may be negative because it must share the costs. But then the profit function is not quasiconcave.
} 
Proof. We first show that at this equilibrium, $p^{\hat{I}}<p^{\bar{I}}(K)$. The first-order conditions are the following for firm 1, and symmetrically for firm 2 .

$$
\begin{aligned}
\frac{\partial}{\partial p_{1}} \bar{\pi}_{1}^{K}\left(p_{1}, p_{2}\right) & \\
= & \frac{\partial}{\partial p_{1}} R_{1}\left(p_{1}, p_{2}\right)-K \frac{\partial}{\partial p_{1}} \bar{\alpha}_{1}\left(p_{1}, p_{2}\right) \\
= & \frac{\partial}{\partial p_{1}} R_{1}\left(p_{1}, p_{2}\right)\left(1-\frac{K}{R_{1}\left(p_{1}, p_{2}\right)+R_{2}\left(p_{1}, p_{2}\right)}\right) \\
& \quad+\frac{K R_{1}\left(p_{1}, p_{2}\right)}{\left(R_{1}\left(p_{1}, p_{2}\right)+R_{2}\left(p_{1}, p_{2}\right)\right)^{2}}\left(\frac{\partial}{\partial p_{1}} R_{1}\left(p_{1}, p_{2}\right)+\frac{\partial}{\partial p_{1}} R_{2}\left(p_{1}, p_{2}\right)\right)
\end{aligned}
$$

If $p_{1}=p_{2} \leq p^{\hat{I}}$, then $\frac{\partial}{\partial p_{1}} R_{1}\left(p_{1}, p_{2}\right) \geq 0$, and $\frac{\partial}{\partial p_{1}} R_{1}\left(p_{1}, p_{2}\right)+\frac{\partial}{\partial p_{1}} R_{2}\left(p_{1}, p_{2}\right) \geq 0$, the latter with strict inequality if the cross partial of $R_{2}$ is positive. Profit is positive if and only if $R_{1}\left(p_{1}, p_{2}\right)\left(1-\frac{K}{R_{1}\left(p_{1}, p_{2}\right)+R_{2}\left(p_{1}, p_{2}\right)}\right)>0$. Therefore, at $p_{1}=p_{2}<p^{\hat{I}},(5.6)$ is zero or positive, depending on whether the cross partial of $R_{2}$ is zero or positive. Since the own derivative $\frac{\partial}{\partial p_{1}} \bar{\pi}_{1}^{K}\left(p_{1}, p_{2}\right)$ is monotonic at symmetric prices, a symmetric equilibrium must therefore satisfy $p^{\hat{I}} \leq p^{\bar{I}}(K)$, with strict inequality if the cross partial of $R_{2}$ is positive.

We now show that $p^{\bar{I}}(K)<p^{\tilde{I}}(K)$. The derivatives satisfy

$$
\begin{aligned}
\frac{\partial}{\partial p_{1}} \bar{\pi}_{1}^{K}\left(p_{1}, p_{2}\right) & \\
= & \frac{\partial}{\partial p_{1}} \tilde{\pi}_{1}^{K}\left(p_{1}, p_{2}\right)-\frac{K R_{1}\left(p_{1}, p_{2}\right)}{\left(R_{1}\left(p_{1}, p_{2}\right)+R_{2}\left(p_{1}, p_{2}\right)\right)^{2}} \\
& \quad-\left(1-\frac{K}{R_{1}\left(p_{1}, p_{2}\right)+R_{2}\left(p_{1}, p_{2}\right)}\right) D_{1}\left(p_{1}, p_{2}\right)
\end{aligned}
$$

Thus, at every symmetric price, $p_{1}=p_{2}, \frac{\partial}{\partial p_{1}} \tilde{\pi}_{1}^{K}\left(p_{1}, p_{2}\right)>\frac{\partial}{\partial p_{1}} \bar{\pi}_{1}^{K}\left(p_{1}, p_{2}\right)$, and similarly for firm 2 , and therefore the only symmetric equilibrium is at higher prices.

That $p^{\hat{I}}(\cdot), p^{\tilde{I}}(\cdot)$ are increasing follows from uniqueness of equilibrium and the monotone-comparative-statics theorems (Theorem 6 of Milgrom and Roberts (1990) or Theorem 13 of Milgrom and Shannon (1994)).

We now return to the question of the vendors' choice of $e$ (and hence $K$.) By the no-hacking constraint, $p_{1}+p_{2} \leq e$, the choice of $e$ can serve as a price cap for the competing vendors. However, Proposition 3 suggests another role for costly 
protection, namely, to give the competing firms an incentive to raise price. The effectiveness of this incentive depends on how much cost the firm can avoid by raising price and decreasing its cost share. If the incentive to pull up prices up to the collusive level $p^{J}$ is strong enough, then the collusive outcome can be achieved by using $e^{J}$ as a price cap. However, there is no reason that prices must be pulled up that far by $K\left(e^{J}\right)$. If not, the firms may choose a level of protection higher than necessary to prevent hacking, as a way to commit to high prices. This strategy also wastes costs.

We now show that whether the firms can support the collusive outcome, and support it without wasting costs, depends on how much of the cost is fixed, that is, independent of the level of protection. We state this result as Proposition 4, and prove it using Lemma 1. We add the following assumption about cost:

Assumption 3. The cost of protection $K(e)$ can be written $K(e)=k+\kappa(e)$ where $\kappa$ is convex, positive, and increasing.

For intuition on how costs affect equilibrium prices, refer to Figure 1. Figure 1 depicts symmetric equilibrium prices $p^{\bar{I}}(\kappa(e))$ for the game with revenue-based cost sharing. Figure 1 shows that the equilibrium price is increasing in $\kappa(e)$, hence increasing in $e$. (A similar diagram for demand-based cost sharing would have the same feature.) Figure 1 also shows that $p^{\bar{I}}(k+\kappa(e))>p^{\bar{I}}(\kappa(e))$ for $k>0$ : if the cost of protection increases, in particular, because the fixed costs increase, the symmetric equilibrium prices also increase.

Part (a) of Lemma 1 says that, for high enough fixed costs, the collusive prices are an equilibrium without wasted costs. That is, if the costs are already high enough, the firms do not have to artificially increase costs by increasing the level of protection $e$ in order to sustain the collusive prices.

Part (b) says that, to achieve the collusive prices without excessive protection $e$, the fixed costs must be even higher with revenue-based cost sharing than with demand-based cost sharing. This is for the reason explored above, that revenue-based cost sharing makes it harder to sustain high prices. Part (b) also says that if the fixed costs are lower than required to achieve the collusive prices without excessive 


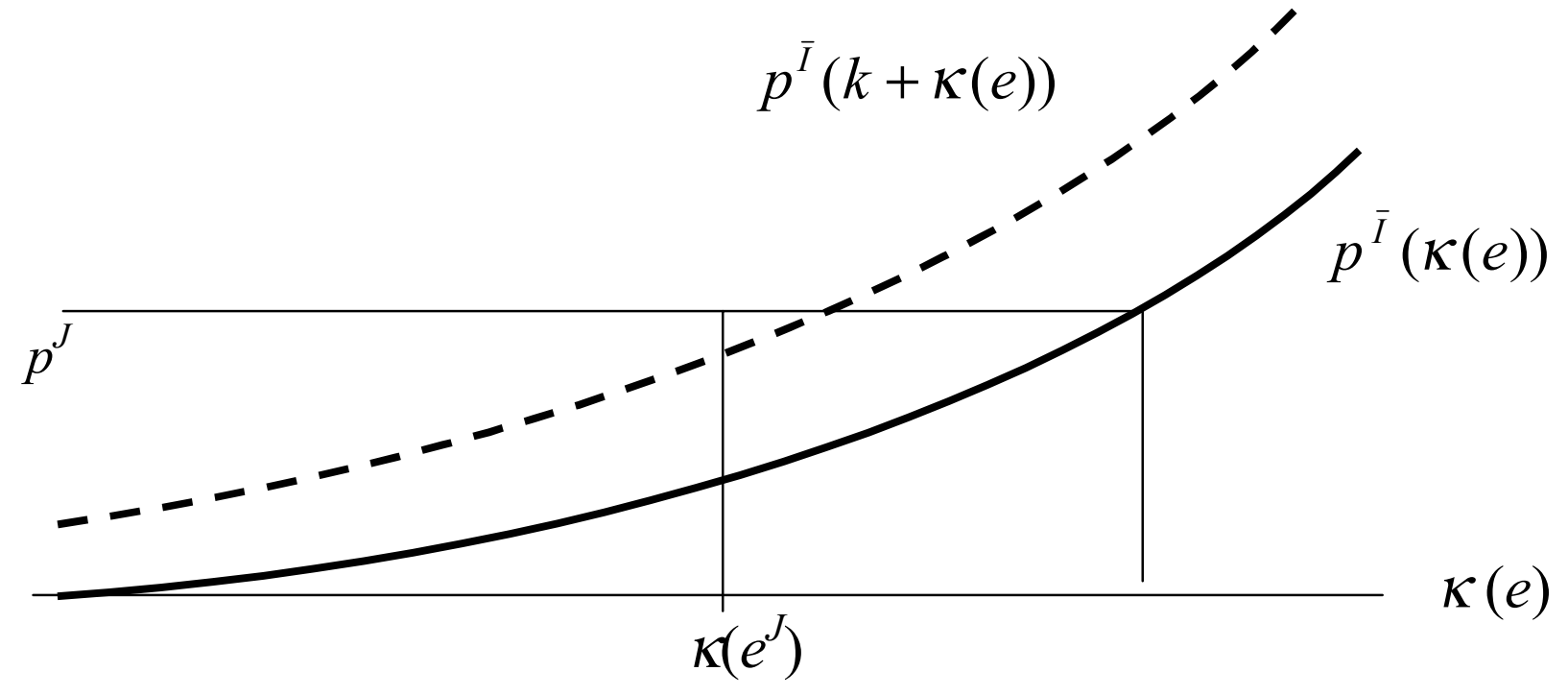

Figure 1: Equilibrium prices increase when the cost of protection increases 
protection, then the firms can either sustain prices below the collusive price or can sustain the collusive price with excessive protection (or, implicitly, some of each).

Part (c) suggests that demand-based cost sharing is more supportive of collusion than revenue-based cost sharing.

Let $p^{J}$ be the optimum of (3.5), using assumption 3. Notice that we can write $p^{J}$ without any ambiguity as $k$ varies, because the optimum does not depend on $k$.

Lemma 1. Suppose that assumptions 2 and 3 hold, that firms make positive profit in equilibrium when $k=0$, and that symmetric equilibrium prices satisfy $p^{\hat{I}}<p^{J}$ and $p^{\hat{I}}, p^{\bar{I}}\left(\kappa\left(e^{J}\right)\right), p^{\tilde{I}}\left(\kappa\left(e^{J}\right)\right)<p^{J}$.

(a) There exist $\tilde{k}, \bar{k}$, with $\bar{k}>\tilde{k}$, such that

$$
\begin{array}{lllrl}
p^{\tilde{I}}\left(\tilde{k}+\kappa\left(e^{J}\right)\right) & =p^{J} & \text { and } & p^{\tilde{I}}\left(k+\kappa\left(e^{J}\right)\right) & \geq p^{J} \text { if } k \geq \tilde{k} \\
p^{\bar{I}}\left(\bar{k}+\kappa\left(e^{J}\right)\right) & =p^{J} & \text { and } & p^{\bar{I}}\left(k+\kappa\left(e^{J}\right)\right) & \geq p^{J} \text { if } k \geq \bar{k}
\end{array}
$$

(b) Given $\kappa(e), \tilde{k}$, and $\bar{k}$ defined above,

$$
\begin{aligned}
& \text { if } k<\tilde{k} \text {, then } p^{\tilde{I}}\left(k+\kappa\left(e^{J}\right)\right)<p^{J} \text {, and } p^{\tilde{I}}(k+\kappa(e))=p^{J} \text { only if } e>e^{J} \text {. } \\
& \text { if } k<\bar{k} \text {, then } p^{\bar{I}}\left(k+\kappa\left(e^{J}\right)\right)<p^{J} \text {, and } p^{\bar{I}}(k+\kappa(e))=p^{J} \text { only if } e>e^{J} \text {. }
\end{aligned}
$$

(c) If $k$ satisfies $\bar{k}>k>\tilde{k}$, then $p^{\bar{I}}\left(k+\kappa\left(e^{J}\right)\right)<p^{J}<p^{\tilde{I}}\left(k+\kappa\left(e^{J}\right)\right)$.

Proof. For Lemma 1(a), we must establish that there exists $\bar{k}$ high enough that the following two conditions hold:

$$
\begin{aligned}
\frac{\partial}{\partial p_{1}} \bar{\pi}_{1}^{\bar{k}+\kappa(e)}\left(p^{J}, p^{J}\right) & =0 \text { and } \\
\bar{\pi}_{1}^{\bar{k}+\kappa(e)}\left(p^{J}, p^{J}\right) & =R_{1}\left(p^{J}, p^{J}\right)\left(1-\frac{\bar{k}+\kappa(e)}{R_{1}\left(p^{J}, p^{J}\right)+R_{2}\left(p^{J}, p^{J}\right)}\right)>0
\end{aligned}
$$

By Proposition 3, the function of $k$ defined by $p^{\bar{I}}(k+\kappa(e))$ is increasing. Let $\bar{k}$ be high enough so that $p^{\bar{I}}(k+\kappa(e))=p^{J}$ as in figure 1, so that (5.8) holds. (In particular, choose $\bar{k}=\frac{\partial}{\partial p_{1}} R_{1}\left(p^{J}, p^{J}\right) / \frac{\partial}{\partial p_{1}} \bar{\alpha}_{1}\left(p^{J}, p^{J}\right)-\kappa\left(2 p^{J}\right)>0$.) Using the expression for the 
derivative given by (5.5) and using $\frac{\partial}{\partial p_{1}} R_{1}\left(p^{J}, p^{J}\right)+\frac{\partial}{\partial p_{1}} R_{2}\left(p^{J}, p^{J}\right)=K^{\prime}\left(2 p^{J}\right)>0$, and remembering that $\frac{\partial}{\partial p_{1}} R_{1}\left(p^{J}, p^{J}\right)<0$, since $p^{J}>p^{\hat{I}}$, (5.8) implies (5.9). A similar argument applies to $\tilde{\pi}_{1}^{\tilde{k}+\kappa(e)}$.

Since $p^{\bar{I}}(k+\kappa(e))<p^{\tilde{I}}(k+\kappa(e))$ by Proposition 3 , and since both prices are increasing in $k$, it follows that $\bar{k}>\tilde{k}$.

Lemma 1(b) follows from Lemma 1(a) and Proposition 3, as follows. By Proposition $3, k<\tilde{k}$ implies $p^{\tilde{I}}\left(k+\kappa\left(e^{J}\right)\right)<p^{\tilde{I}}\left(\tilde{k}+\kappa\left(e^{J}\right)\right)$, hence $p^{\tilde{I}}\left(k+\kappa\left(e^{J}\right)\right)<p^{J}$. Now suppose $p^{\tilde{I}}(k+\kappa(e))=p^{J}$ for some arbitrary $e$, and $k<\tilde{k}$. As $\kappa(e)$ is increasing in $e, p^{\tilde{I}}\left(k+\kappa\left(e^{J}\right)\right)<p^{\tilde{I}}(k+\kappa(e))=p^{J}$ implies $e>e^{J}$. A similar argument applies for $p^{\bar{I}}(k+\kappa(e))$.

$2(\mathrm{c})$ follows from $2(\mathrm{a})$ and $2(\mathrm{~b})$.

We consider the case that $p^{\hat{I}}<p^{J}$, since otherwise collusion should not be much of a concern.

Proposition 4 (The collusive effect of cost sharing). Suppose that assumptions 2 and 3 hold and that $p^{\hat{I}}<p^{J}$.

(a) Regardless of whether the vendors share costs according to revenue or demand, for high enough fixed costs of protection (high enough $k$ ), the equilibrium price will be the collusive price $p^{J}$, and $e^{J}=2 p^{J}$.

(b) Demand-based cost sharing supports the collusive price whenever revenue-based cost sharing does so, but not vice versa.

(c) The firms' equilibrium profits are higher (no lower) with demand-based cost sharing than with revenue-based cost sharing.

Proof. (a) follows from Lemma 1(a).

(b) follows from Lemma 1(c).

(c) Given $e$, there are three cases:

$$
\begin{aligned}
& p^{J}(K(e))<p^{\bar{I}}(K(e))<p^{\tilde{I}}(K(e)) \\
& p^{\bar{I}}(K(e))<p^{J}(K(e))<p^{\tilde{I}}(K(e)) \\
& p^{\bar{I}}(K(e))<p^{\tilde{I}}(K(e))<p^{J}(K(e))
\end{aligned}
$$


If the first case applies at $e=e^{J}$, the firms can support the collusive price without waste, using either demand-based or revenue-based cost sharing. If the second case applies at $e=e^{J}$, demand-based cost sharing can support the collusive price without waste, but revenue-based cost sharing cannot. If the third case applies at $e=e^{J}$, the collusive prices cannot be supported without waste, with either demand-based or revenue-based cost sharing. But a higher price can be supported at each $e$ with demand-based cost sharing than with revenue-based cost sharing. Since joint profit is rising in the symmetric price for $p<p^{J}$, the higher price is more profitable.

\section{Collusion through Technology}

Because the technological capability of the DRM system has important effects on prices, the technology deployed should not be irrelevant to the antitrust authorities. The vendors, users, and antitrust authorities will typically have different preferences as to which capabilities should be deployed. But it is not obvious what the right antitrust objective should be, given that the protected content generally has copyright protection in the first place, and given that the DRM system will dissipate profits that might otherwise reward creators for creating their content. Should the antitrust objective be one of $p^{J}, p^{I}, p^{\hat{I}}$, perhaps the lowest one? Or should the antitrust objective be explicitly procedural, such as insisting that the vendors implement independent systems? Should the antitrust authorities allow a shared system only under the proviso that the technology facilitate independent pricing? Should it at the same time create rules as to royalties or cost sharing?

As we pointed out in Remark 3, the prices $p^{I}$ that result from independent protections may or may not be lower than the collusive price with a shared system, $p^{J}$. But even if higher, the vendors' profit may be lower because the costs of protection are higher. Thus, the antitrust authorities cannot avoid the tradeoff between incentives for vendors and access for users at low prices.

In the previous section we showed that competition between the vendors sharing a system is affected by two important aspects of the governance structure: 
- whether they set prices independently, and

- how they share costs.

Independent pricing is surely the most important aspect: if the subsidiary sets prices on behalf of the vendors jointly, or sets a royalty that is then redistributed to the vendor-owners of the DRM subsidiary, it will surely support the collusive prices $p^{J}$. Whether there is independence in price-setting depends on the technological capabilities of the DRM system, but the incentive to price competitively also depends on the cost sharing arrangement.

But if independent pricing is the objective, how can it be assured? A natural scheme would be to create a technical capability for each vendor to key in its own price, unrelated to the other vendors' prices. As we argued at the end of the last section, that system may or may not sustain the collusive price $p^{J}$, depending partly on how costs are shared. It is more likely to sustain the collusive price if the vendors share cost according to demand rather than revenue. If low prices are the goal, the antitrust authorities may favor revenue-based cost sharing.

Suppose, on the other hand, that a DRM system that decrypts and authorizes through a call-home system imposes a price-per-view for all content (or charges a royalty per view,) and distributes the net profit to the vendors proportionately to the revenue generated by the content. If the DRM can implement a single price, it is reasonable to suppose that, acting on behalf of its vendor-owners, the subsidiary would choose the profit-maximizing price and level of protection. In the symmetric case considered here, the best price would be the first-best collusive outcome (although a common price would be a second-best solution if content varied in popularity). The vendors would surely approve if the DRM system implemented this, at least if it could prevent cheating.

But the DRM cartel, like all cartels, must worry about price cutting. An obvious way for a vendor to cheat the cartel is to offer rebates to customers outside the system, and thus increase its demand. This would ordinarily be a capability favored by antitrust authorities, but it comes at the price of privacy. The vendors can only circumvent the common price with rebates if they know who the purchasers 
are. In choosing the technical capabilities of the DRM system, there may be a conflict between privacy and competition policy. In yet another twist, however, rebates on the side cannot be reflected in the cost sharing scheme, which will have to be demand-based rather than revenue-based. We have already shown that demand-based cost sharing has greater potential to support the collusive price, and vendors may therefore forego the opportunity to make rebates, even if that were possible.

Finally, it is possible that the subsidiary covers the costs of the protection system by charging a royalty per view, while the vendors charge independent prices. But unless the DRM system is "rate regulated," there will still be profit or loss which must be apportioned between the vendors. If the subsidiary charges a royalty equal to the collusive price, and if the total profit or loss is apportioned according to revenue shares, then the vendors' individual profits are their own revenues minutes revenuebased cost shares. The vendors will prefer the collusive outcome, but will have an incentive to break the royalty-supported cartel, for example, by making price rebates, in the same circumstances as with revenue-based cost sharing.

\section{Conclusions and Open Questions}

In addition to exploring price consequences of a shared DRM system, we also explored the divergence between the private incentive to create a shared system and the circumstances in which that would be efficient. There are two incentives for content providers to share a system. One is that it saves the fixed costs of implementing and administering the system. The other is that it may give them an opportunity for coordinated or collusive pricing. One of these is in the public interest, and the other may not be. But collusive pricing is less a threat than it appears because a shared system is an attractive target for circumvention, and the firms can reduce circumvention by lowering prices. In addition, the technology might conceivably maintain independence in pricing, which has some potential for avoiding collusion, especially if cost shares are based on revenue rather than demand. Of course the vendors would not typically want to choose a technical system that avoids collusion.

The welfare implications are ambiguous. Technical protections are expensive. 
The expense is a social waste, as compared to perfect legal enforcement. Content providers are burdened in two ways: by the cost of protection and by the lower prices they receive for access to the content. In the end, smaller rewards for content providers will mute the creative impulse. Nevertheless, we have found a silver lining, namely, that the threat of hacking leads to lower prices, whether vendors choose independent systems or collude through a shared system.

The pricing options we have investigated do not exhaust the possibilities suggested in the introduction. The systems we have considered govern the pricing of content, rather than players, and content itself can be priced in different ways, depending on how use can be metered. Content today can be purchased on physical media, giving the right to unlimited or only a few viewings, or it can be purchased on a per-viewing basis such as video-on-demand. Subscription services like cable television bundle these services in yet another way, by giving unlimited viewings per unit time. Basing royalties on usage has the virtue of taxing the more popular content and the higher-demand users more highly. It may thus reduce distortions as compared, for example, to putting the royalty on media players or charging a fixed royalty per unit time. Taxing the media players will presumably create distortions at the "extensive margin," that is, in the number of users in the market. The competitive effects of what is priced have not yet been explored.

\section{Appendix: Prices with Dispersion in Circumvention Costs}

In this appendix, we show that the price-reducing effect of a threat of circumvention holds also with dispersion in circumvention costs, with the difference that there will be circumvention in equilibrium, which compounds the profit loss.

We define an "effective" demand curve that recognizes that some agents may circumvent rather than buy legitimate copies. To define the effective demand curve, assume that each user will buy if both his willingness to pay and his personal cost of circumvention, say $c$, are higher than the price. Agent $\theta$ will buy if $\theta, c \geq p$. He will circumvent if both his willingness to pay and the price are higher than his cost of circumvention, $\theta, p \geq c$. Suppose that the costs of circumvention are distributed 
according to a distribution function $G$ with density $g$, independently of $\theta$, such that, if $e>e^{\prime}$, then $G(\cdot ; e)$ stochastically dominates $G\left(\cdot ; e^{\prime}\right) .{ }^{6}$ At the price and protection $(p, e)$, the demand for legitimate copies is

$$
(1-p)(1-G(p ; e))
$$

The term $(1-p)$ represents the fraction of consumers for whom willingness to pay is higher than the price, and the term $(1-G(p ; e))$ represents the fraction for whom the circumvention cost is higher than the price.

The proprietor's profit is

$$
\Pi(p, e)=p(1-p)(1-G(p ; e))-K(e)
$$

For each $e$, let $p(e)$ be the price that maximizes $\Pi(p, e)$. Given this setup, we can prove the following:

Remark 4. When the costs of circumvention are dispersed, for every $e, p(e)<p^{*}$. Suppose that the costs of circumvention are uniformly distributed with expected value $e$ when the protection level is $e$. If $\hat{e}, \tilde{e}$ are respectively the profit-maximizing protection levels when circumvention costs are not dispersed and when dispersed uniformly, then $p(\tilde{e})<\hat{e}<p^{*}$.

Since $\Pi(p, e)<p(1-p)$ at every $p, e$, profit is smaller with technical protection than with perfect legal enforcement. The optimal proprietary price, say $p(e)$, maximizes (8.1), conditional on the level of protection $e$, and satisfies

$$
\left.\frac{\partial}{\partial p} \Pi(p, e)\right|_{p=p(e)}=\left.\left[(1-G(p ; e)) \frac{\partial p(1-p)}{\partial p}-p(1-p) g(p ; e)\right]\right|_{p=p(e)}=0
$$

Since the derivative is negative whenever $\frac{\partial p(1-p)}{\partial p} \leq 0$, the optimal price $p(e)$ is lower than the monopoly price, $p^{*}=\frac{1}{2}$, regardless of $e$.

The proprietor also optimizes with respect to the level of protection $e$. The derivative of $\Pi$ with respect to $e$ is

$$
\left.\frac{\partial}{\partial e} \Pi(p, e)\right|_{p=p(e)}=-p(1-p) \frac{\partial G(p ; e)}{\partial e}-K^{\prime}(e)
$$

\footnotetext{
${ }^{6}$ That is, $G\left(c ; e^{\prime}\right)>G(c ; e)$ for every $c$ in the support of $G$.
} 
The first term, which is positive since $\frac{\partial G(p ; e)}{\partial e}<0$, represents the saved revenue due to a decrease in circumvention if $e$ is increased, and the second term represents the marginal cost. Combining with (8.2),

$$
\left.\frac{\partial}{\partial e} \Pi(p, e)\right|_{p=p(e)}=\left.\frac{-(1-G(p ; e))}{g(p ; e)} \frac{\partial G(p ; e)}{\partial e} \frac{\partial p(1-p)}{\partial p}\right|_{p=p(e)}-K^{\prime}(e)=0
$$

It is easy to see in an example that dispersion in circumvention costs can cause the proprietor to charge a lower price than without dispersion. Suppose that $K^{\prime}$ is increasing and that the distribution of circumvention costs is uniform on an interval around the strength of protection $e$ :

$$
\begin{aligned}
& G(p ; e)= \begin{cases}0 & \text { if } \quad p<e-\frac{1}{2} \\
p-e+\frac{1}{2} & \text { if } \quad e-\frac{1}{2}<p<e+\frac{1}{2} \\
1 & \text { if } \quad p>e+\frac{1}{2}\end{cases} \\
& g(p ; e)=1 \quad \text { for } e-\frac{1}{2}<p<e+\frac{1}{2}
\end{aligned}
$$

It follows from (8.3) that the optimal $(p, e)$ entails both circumvention and purchases, so that $0<1-G(p ; e)<1$. It follows from $(8.2)$ that $p(e)$ is increasing with $e$. In $(8.4), \frac{(1-G(p ; e))}{g(p ; e)} \frac{\partial G(p ; e)}{\partial e}$ is less than one. It then follows from $(8.4)$ that the optimal strength of protection is smaller when circumvention costs are dispersed than when not, as follows.

Let $\tilde{e}$ be the optimal protection when circumvention costs are dispersed, and $\hat{e}$ when not. Then $\left.\frac{\partial p(1-p)}{\partial p}\right|_{p=\hat{e}}=K^{\prime}(\hat{e})$. It follows from $(8.4)$ that $p(\hat{e})<\hat{e}$. (In fact, at any given protection level $e$, not only $\hat{e}$, the optimal price is lower with dispersed circumvention costs than with no dispersion.) Then if $\tilde{e}<\hat{e}$, it follows that $p(\tilde{e})<$ $p(\hat{e})<\hat{e}$; the optimal price is lower with dispersed circumvention costs than not. Suppose instead that $\hat{e} \leq \tilde{e}$, which implies that $K^{\prime}(\hat{e}) \leq K^{\prime}(\tilde{e})$ and $p(\hat{e}) \leq p(\tilde{e})$. Then using (8.4), it follows that $\left.\frac{\partial p(1-p)}{\partial p}\right|_{p=p(\tilde{e})}>\left.\frac{\partial p(1-p)}{\partial p}\right|_{p=\hat{e}}$ which again implies that $p(\tilde{e})<\hat{e}$.

Thus, in a plausible example, dispersion in the costs of circumvention decreases the price of content, but also decreases the proprietor's profit. In addition, there will be consumers who circumvent the protection in equilibrium, adding to social costs. 
Consumers' surplus plus profit in each period, designated $W(p, e)$, is

$$
\begin{aligned}
W(p, e) & =s(p)+p(1-p)+\int_{0}^{p} \theta G(\theta ; e) d \theta-C(p, e) \\
& =\int_{p}^{1} \theta d \theta+\int_{0}^{p} \theta G(\theta ; e) d \theta-C(p, e)
\end{aligned}
$$

where $C(e ; p)$ is the total cost of circumventions that occur in equilibrium:

$$
C(p, e)=\int_{0}^{1}\left(\int_{0}^{\min \{p, \theta\}} c d G(c ; e)\right) d \theta
$$




\section{References}

Ayres, I., and P. Klemperer. 1999. "Limiting Patentees' Market Power without Reducing Innovation Incentives: The Perverse Benefits of Uncertainty and Noninjunctive Remedies." Michigan Law Review 97:985-1033.

Belleflamme, P. 2003. "Pricing Information Goods in the Presence of Copying." W.J. Gordon, R. Watts, eds. The Economics of Copyright: Developments in Research and Analysis. Edward Elgar Publishers.

Besen, S., and S. Kirby. 1989. "Private Copying, Appropriability and Optimal Copyright Royalties." Journal of Law and Economics 32:255-275.

Chen, Y. and I. Png. 2003. "Information Goods, Pricing, and Copyright Enforcement: Welfare Analysis" Information Systems Research 14:107-123

Conner, K. R. and R. P. Rumelt. 1991. "Software Piracy: An Analysis of Protecting Strategies." Management Science 37:125-139.

Conseil de la Concurrence. 2004. Press Release regarding VirginMega v. Apple Computer.

Gayer, A. and O. Shy. 2004. "Publishers, Artists and Copyright Enforcement." Mimeograph. Haifa, Israel: Department of Economics, University of Haifa.

Johnson, W. R. 1985. "The Economics of Copying." Journal of Political Economy 93:158-174.

Kaplow, L. 1984. "The Patent-Antitrust Intersection: A Reappraisal." Harvard Law Review 97:1813-1892.

Klein, J. 1997 "Trustees of Columbia University, Fujitsu Ltd., General Instruments Corp., Lucent Technologies Inc., Matsushita Electric Industrial Co. Ltd., Mitsubishi Electric Corp., Philips Electronics N.V., Scientific-Atlanta Inc., and Sony Corp., Cable Television Laboratories Inc., MPEG LA L.L.C." United States Department of Justice Business Review Letter.

Klein, J. 1999 "Hitachi, Ltd., Matsushita Electric Industrial Co., Ltd., Mitsubishi Electric Corp., Time Warner Inc., Toshiba Corp., and Victor Company of Japan, Ltd." United States Department of Justice Business Review Letter. 
Milgrom, P., and Roberts, J. 1990. "Rationalizability, Learning, and Equilibrium in Games with Strategic Complementarities." Econometrica 58:1255-1277.

Milgrom, P., and Shannon, C. 1994. "Monotone Comparative Statics." Econometrica $67: 157-180$.

Novos, I., and M. Waldman. 1984. "The Effects of Increasing Copyright Protection: An Analytic Approach." Journal of Political Economy 92:236-246.

Scotchmer, S. 2004. Innovation and Incentives. Cambridge, MA: MIT Press.

Shapiro, C. 2001. "Navigating the Patent Thicket: Cross Licenses, Patent Pools, and Standard-Setting." Innovation Policy and the Economy 1:119-150.

Shy, O. and J.-F. Thisse. 1999. "A Strategic Approach to Software Protection." Journal of Economics and Management Strategy 8:163-190.

Sundararajan, Arum. 2004. "Managing Digital Piracy: Pricing, Protection and Welfare." Working paper. New York: Stern School of Business, NYU.

Tandon, P. 1982. "Optimal Patents with Compulsory Licensing." Journal of Political Economy 90:470-486. 